\title{
Un acercamiento geocrítico a Carta magna de América: la creación de los espacios americanos en la poesía de Pablo de Rokha
}

\author{
José Miguel Curet \\ Universidad de Puerto Rico
}

Resumen: Este trabajo propone un análisis geocrítico de Carta magna de América (1949) del poeta chileno Pablo de Rokha. El título del poemario sugiere que nos enfoquemos en las relaciones entre la poética rokhiana y la formación y representación de los espacios americanos. La poética de esta obra toma la forma de un sistema de creación estética y de un sistema integral de representación de espacios alternos sustitutivos de los espacios neocoloniales predominantes en América Latina para la década del cuarenta. De igual manera, su sistema cartográfico poético está articulado dentro de un sistema de sistemas semiótico más abarcador. En la lectura del poemario, esta peculiaridad permite desenmascarar los procesos políticos, económicos, sociales y culturales de la época. Así, Carta magna de América debe ser entendido como una unidad que conforma un sistema de referencia espacial creativo, poético y político cuyos componentes y planteamientos están estrechamente ligados entre sí. Este sistema múltiple postula la redefinición, la re-expresión, la reacción, la crítica, la articulación y la reconquista de los tiempos y espacios humanos en los cuales se gestó su producción. El poemario muestra una poética que crea el mundo y sus fronteras con la palabra que enuncia su voz. El modelo geocrítico de análisis literario e interpretación cultural nos proporciona una perspectiva geocentrada de las referencias poéticas y de los referentes a los espacios americanos y chilenos. Nuestro análisis se dirige hacia el entendimiento de estos nuevos espacios de convivencia que se formulan en los poemas. Además, consiente poner de relieve los procesos de descolonización y captar la apertura creativa y poética a múltiples representaciones sobre el mundo y el transcurrir del tiempo.

Palabras clave: Pablo de Rokha, Poesía Chilena, Geocrítica, Mapas Poéticos 
Résumé: Ce travail propose une analyse géocritique de Carta magna de América (1949) du poète chilien Pablo de Rokha. Le titre du recueil de poèmes suggère qu'on se focalise dans les relations entre la poétique rokhienne et la formation et la représentation des espaces américains. La poétique de cette œuvre prend la forme d'un système de création esthétique et d'un système intégral de représentation des espaces alternes substitutifs des espaces néocoloniaux qui dominaient en Amérique Latine dans les années quarante. Également, son système poétique-cartographique est articulé à l'intérieur d'un système des systèmes sémiotique plus vaste. Dans la lecture du recueil, cette particularité permet de démasquer les procès politiques, économiques, sociaux et culturels de l'époque. Ainsi, Carta magna de América doit être compris comme une unité qui conforme un système de référence spatial, créatif, poétique et politique dont ses composants et ses démarches sont étroitement liés. Ce système multiple propose la redéfinition, la réexpression, la réaction, la critique, l'articulation et la reconquête des temps et des espaces humains où sa production s'est faite. Le recueil montre une poétique qui crée le monde et ses frontières avec la parole qui énonce sa voix. Le modèle géocritique d'analyse et interprétation culturelle nous donne une perspective géocentrée des références poétiques et des référents aux espaces américains et chiliens. Notre analyse se dirige vers la compréhension de ces nouveaux espaces de coexistence formulés par les poèmes. La géocritique consent aussi de mettre en relief les processus de décolonisation et d'aperture créatrice et poétique aux multiples représentations du monde et du déroulement du temps.

Mots-clés: Pablo de Rokha, Poésie Chilienne, Géocritique, Carte Poétique

En este trabajo proponemos una lectura geocrítica del poemario Carta magna de América del poeta chileno Pablo de Rokha, publicado por primera vez en 1949. Como sugiere el título de esta obra, nos centramos en las relaciones entre la poética rokhiana, la creación de los espacios americanos y sus representaciones. Hay que destacar que su escritura y sus ediciones coinciden con los años en los cuales el paradigma espacial entorno al acontecer humano suplantó definitivamente al paradigma temporal. Según argumenta Bertrand Westphal en el ensayo "Pour une approche géocritique des textes, esquisse", por un largo periodo en la cultura occidental, el tiempo fue la coordenada principal de la inscripción del ser humano en el mundo y el espacio resultaba marginal. El espacio se concebía como si fuese un simple contenedor. Westphal añade que este sólido paradigma 
fundado en la noción del tiempo se debilitó al finalizar la Segunda Guerra Mundial. Luego de 1945, el espacio se convirtió en un elemento primario para las representaciones del ser humano sobre el mundo (apud Westphal 2000: 9-10). Esta coincidencia no es nada más un asunto de fechas y casualidades. La representación del espacio en la creación literaria se convirtió en una fuerte tendencia en Chile, América Latina, Estados Unidos y Europa. La poética planteada por Pablo de Rokha parte desde esa reconceptualización de la escritura en donde su eje central es la reformulación de las imágenes de los espacios humanos que la sitúan en un contexto particular y hacen entendibles sus posicionamientos políticos y culturales. Dentro de la dinámica establecida entre la experiencia individual del sujeto poético y sus representaciones de los espacios americanos, la obra rokhiana logra articular una cartografía poética alterna y revolucionaria de refundación continental.

Antes de continuar, conviene clarificar brevemente la situación con el título, los años de publicación, las maneras en que se editó y nuestra preferencia por el título Carta magna de América. Este extenso poemario se publicó por primera vez en 1949 en la Editorial Multitud con el título 3 poemas por Pablo de Rokha dentro del libro Arenga sobre el arte. ${ }^{1}$ En esta edición, el poemario está acompañado de una colección de ensayos de estética, filosofía y arte escritos por el autor y por otro poemario, El valle pierde su atmósfera, de Winétt de Rokha. ${ }^{2}$ En 1954, De Rokha incluyó de manera íntegra su poemario en Antología 1916-1953 y le cambió el título a Carta magna de América ${ }^{3}$. En esta segunda edición, el contenido de los poemas no se altera, solamente se modifican el título de la obra y los títulos de tres poemas 4 . Posteriormente, cuando el autor se refiere a este poemario con el nombre de Carta magna de continente, aunque nunca se publicó con este título5. Para nuestro análisis, decidimos referirnos a la obra como Carta magna de América, pero trabajando y citando la versión de 3 poemas por Pablo de Rokha, aparecida en Arenga sobre el arte. El título Carta magna de América explica y sintetiza su poética. Referirnos así es un elemento crucial para la afirmación y preservación de las propuestas sobre la rearticulación, representación y refracción poética global de las imágenes de América. Además de brindar cohesión y transmitir la expresión de totalidad americana, va acorde con las intenciones de nuestra lectura geocrítica. 
Para encausar nuestro análisis, citamos un fragmento de "Retrato furioso". Este primer poema de la colección revela el rumbo de nuestra lectura:

Como un ataúd que volara y cruzara el gran océano des-

de para siempre,

mi poema no tiene edad ni dimensión, existe a la manera in-

mortal del universo y sus catástrofes, no tuvo prin-

cipio ni fin, aunque de origen piojoso e hidalgo es-

pañol con indio adentro

y va cargando con la voluntad del mundo, con el mundo en las

alforjas,

edificando con los anhelos de la época la estatua de la época

y llorando los llantos tronchados y acumulados de

las escrituras en un escrito lleno de huevos de toro

exactamente que hablasen los vivos y los muertos cuando yo hablo. (De Rokha 1949: 230)

En este fragmento y a largo de Carta magna de América, la voz poética declara que sus poemas no tienen edad ni dimensión. Insiste que su creación existe a la manera inmortal del universo porque su obra no tiene principio ni fin. Su intención principal es hacer los vocabularios del destino con las verdades y las pasiones que carga junto con la voluntad del mundo. Inserto en de esta dialéctica, los poemas edifican la representación alterna de sus espacios. En el momento que la voz poética consigue levantar la estatua de su época, es decir, codificar sus espacios de existencia situado de sus anhelos, su voluntad y su ideología, el acto poético-cartográfico deviene un acto político.

Teniendo en cuenta que la voz poética busca instaurar sus espacios mediante su acto poético-cartográfico al mismo tiempo que afirma la existencia a la manera inmortal del universo, hay que preguntarse: ¿cómo entender la relación de la voz poética con la realidad americana y cómo sería posible ponerla en perspectiva con sus propósitos de totalización continental desde la poesía? ¿En dónde situarse y cómo enfrentar una poética que aspira a expresar la magnitud del universo infinito desde sus experiencias en el cosmos americano? Por otro lado, la carta magna que configura Carta magna de América reivindica que la praxis de crear las nuevas representaciones (lingüísticas, poéticas y políticas) de los espacios y 
tiempos americanos debe derivarse orgánicamente de todo su historial de coloniaje, saqueo y catástrofes, de todos sus contextos y áreas sociales, culturales, políticas y económicas de explotación en donde se localiza el sujeto poético. Entonces, cómo seguir los pasos de este estilo poético transformado en una cartografía americana. ¿Qué tipo de lectura realizar para no perdernos en su peripecia de reconquista y refundación del continente?

La aproximación geocrítica de Bertrand Westphal propulsa un método de análisis cultural en donde se puedan leer las ciudades y con el cual se consiga reflexionar sobre la fabricación de los espacios humanos de la misma manera que se recorre un texto poético o literario, y a la inversa (apud Westphal 2000: 11). Siguiendo a Westphal, percibimos que Carta magna de América no solo traza un paralelo entre su escritura y la topografía urbana, sino que la escritura traza un paralelo entre su poética y una geografía continental. En este acto de cartografía continental, debemos estar atentos a cómo se incorpora el florecimiento de la multiplicidad de miradas sobre el mundo y cómo esa multiplicidad de miradas influencia y se plasma en sus representaciones del continente. En el poema "Surlandia, pulso del mundo o 'lamento americano de las colonias'" podemos leer unos ejemplos de esta cartografía múltiple y continental:

Oro y piojos a la manera de un tambor funeral de aden-

tro de la majestad de los pueblos surgiendo, salitre y piojos, petróleo y piojos, diamantes y piojos...

...piojos andando por

los sobacos y los espinazos sudados del Continente que es un buey comiéndose a una piedra

adentro de los pueblos piojentos y completamente inmensos de Chile y de Méjico, del Perú y del Uruguay, del Ecuador ... (...) miseria sobre riqueza y piojos macabros como un zapato que echase una flor, piojos sobre los negros, piojos sobre los rojos, piojos sobre los blancos, piojos sobre los mestizos, piojos sobre los mulatos, en la Florida y la Carolina del Sur, piojos, en Harlem de New York, piojos y piojos de piojos... en la camisa de fuego de América, con horroroso resplandor, 
en donde patrones y peones dan la batalla social, los primeros como verdugos, los segundos como obreros son los torsos heridos por el sol de Dios, por el cual camina solo un piojo enorme como el mundo: el piojo del corazón... (De Rokha 1949: 234-235)

En este poema, el plano espacial y sus referentes se perciben como protagonistas. Se logra reivindicar al continente americano frente a los procesos históricos mundiales que han definido sus realidades. Aquí se hace evidente la representación de una bipartición del mundo en donde la alteridad surgida de la multiplicidad de miradas está en un conflicto constante contra el centro hegemónico heredero o producto de los dominios imperiales, coloniales, neocoloniales y postcoloniales.

La amplitud interpretativa del acercamiento geocrítico de Westphal otorga los elementos necesarios para adentrarse en la rebuscada y provocadora poética rokhiana. Asimismo, elabora los conceptos para señalar la relevancia de Carta magna de América en el acontecer literario, cultural y político de su época. Westphal define brevemente la geocrítica de la siguiente manera:

1. Geocriticism is geo-centered rather than ego-centered approach; that is, the analysis focused on global spatial representations rather than on individual ones...

2. Geocriticism ceases to privilege a given point of view in order to embrace a broader range of vision regarding a place.

3. Geocriticism promotes the empire of the senses, a polysensuous approach to places- places meaning concrete or realized spaces.

4. Geocriticism associates both geometric and philosophical coordinates of life -time and space- in a spatiotemporal scheme. A geocritical analysis locates places in a temporal depth in order to uncover or discover multilayered identities, and it highlights the temporal variability of heterogeneous spaces. All this is in line with three fundamental concepts: spatiotemporality (no spatial analysis may avoid temporal concerns); Transgressivity (no representation is stable; on the contrary, as in Deleuze's deterritorialization process, permanent fluidity is the characteristic of representation and, consequently, of identities); and referenciality (any representation is linked with the referential world). (Westphal 2011: xiv-xv) 
Conviene acercarnos a Carta magna de América de la forma en que propone Westphal. Para aproximarnos a las representaciones espaciales rokhianas, se debe adoptar una mirada geocentralizada y múltiple. Por su naturaleza composicional, De Rokha nos obliga al reconocimiento de la diversidad de puntos de vista sobre los espacios geográficos, humanos y sociales a los que se consagra su poética. La sensorialidad de la experiencia es un componente principal en la representación poética de estos espacios. Esta sensorialidad de la experiencia es reveladora, sobre todo, en el poema "Teogonía y cosmología del libro de cocina" (De Rokha 1949: 295-316). Tanto las coordenadas geométricas y de localización, así como las argumentaciones filosóficas son necesarias para destapar y descubrir las múltiples identidades y las variaciones temporales de los espacios heterogéneos y los espacios por hacerse desde el razonamiento poético. En la lectura hay que tener en cuenta la espaciotemporalidad, la transgresividad y la referencialidad. Pensamos que estas tres nociones subrayan el predominio del aspecto político de Carta magna de América. Además, resaltan su vigencia en el desarrollo literario y cultural del siglo veinte en América.

Para Westphal, el espacio debe ser aprehendido en su doble tensión centrífuga y centrípeta. Con esta doble tensión en cuenta, se logra que el entendimiento sobre los espacios suelte el ancla que lo fijaba siempre a la inmovilidad, a la invariabilidad, a la fijeza, a la estabilidad y a la permanencia. Una vez perdido este anclaje, se consigue la observación y el comentario de la evanescencia que permea constantemente en los espacios (apud Westphal 2000: 14). Carta magna de América es claramente un levantamiento de ancla. También, es el registro de un trayecto histórico y espacial que posibilita la bipartición de las miradas sobre el mundo americano. "Retrato furioso", comienza aludiendo a la movilidad, al viaje del sujeto poético y su evanescencia:

\footnotetext{
Empuño tu nombre como una canción nunca escrita o como pañuelo de viajero, en este instante alto y ancho con la altura y la anchura total de un ataúd y un sudor popular de muchedumbre a las médulas agarrado como el manotazo del atardecer surge el galope ho-
} 
rripilante de tabla de náufrago desde el ser espinal

del orbe a la criatura de peripecia

que soy yo solo, exacto, indescriptible... (De Rokha 1949: 221)

Carta magna de América es la inscripción de este viaje. En su itinerario, la voz plantea las representaciones poéticas de los espacios que recorre y con las cuales es posible la evanescencia de una visualización cartografía desde cual proceden los mapas poéticos rokhianos. Una geocrítica sobre Carta magna de América debe articular o abarcar primordialmente las complejidades de las interacciones de la obra poética con sus espacios de producción, sus referentes, coordenadas intertextuales y metatextuales y comunidades culturales.

Westphal sostiene el argumento del levantamiento de ancla y el paso a la movilidad de los espacios en el tiempo a partir del razonamiento de Gilles Deleuze y Félix Guattari en Mille plateaux (1980) y Qu'est-ce que la philosophie? (1991). Para la geocrítica es decisivo dar cuenta de la complejidad y amplitud de la captación de los espacios. Citando a Mille plateaux de Deleuze y Guattari, Westphal apunta que:

Gilles Deleuze et Félix Guattari avaient élaboré une théorie qui mieux que d'autres rendait compte de la complexité de toute saisie des espaces humains. Ils évoquaient la ligne de fuite inhérente à tout territoire, fût-il étroitement délimité, et posaient la question cruciale : « il faudrait d'abord mieux comprendre les rapports entre D (déterritorialisation), territoire, reterritorialisation et terre ». Et d'ajouter :

'En premier lieu, le territoire lui-même est inséparable de vecteurs de déterritorialisation qui le travaillent du dedans [...] En second lieu, la D est à son tour inséparable de reterritorialisations corrélatives. C'est que la D n'est jamais simple, mais toujours multiple et composée [...] Or la reterritorialisation comme opération original n'exprime pas un retour au territoire, mais ces rapports différentiels intérieurs à la $\mathrm{D}$ elle-même, cette multiplicité intérieure à la ligne de fuite [...] Au point que la D peut être nommée créatrice de la terre - une nouvelle terre, un univers, et non plus seulement une reterritorialisation'. (Deleuze/ Guatarri 1980: 635)

Par conséquent, le territoire apparaît bien comme " un tenir-ensemble d'éléments hétérogènes », qu'il conviendra d'observer dans leur mouvance. (Westphal 2000: 14-15) 
En Carta magna de América, el territorio es justamente un conjunto de elementos heterogéneos que se distinguen por su movilidad. Al igual que se articula en la geocrítica, el poemario rokhiano disocia el espacio de su aspecto fijo acercándolo a la temporalidad que transcurre y provoca el cambio constante de las realidades americanas. Múltiple y compuesta, como declaran Deleuze y Guattari, reconocemos que la poética cartográfica de Carta magna de América equivaldría a esa $D$ creativa de la desterritorialización. Siguiendo siempre una línea de fuga, América en Carta magna de América se convierte en la creación de una nueva tierra, un universo que es un nuevo cosmos americano en el cual existir y experimentar los cambios continuos de los espacios. La acción poética es la creadora incesante del mapa del cosmos americano en la cual transcurre su praxis. Hay que tomar en consideración estos espacios americanos desde su movilidad y la segmentación de su línea de fuga que se extiende hasta la representación de las concepciones del cosmos.

América está considerada en cuanto continente contenedor de las revelaciones de una infinita multiplicidad abocada al cosmos. De más está decir que ahí se tejen redes o se desprende una continuidad de puntos que se navegan. América es un continente semejante a un archipiélago o a una constelación. Una lectura geocrítica de Carta magna de América debe asumir esta movilidad del espacio y someter su fragmentación a una velocidad infinita de nacimiento y de desvanecimiento y buscar el umbral de su suspensión del infinito. Tanto Westphal al proponer la geocrítica como Pablo de Rokha al esgrimir su poética, concuerdan en la multiplicidad de percepciones espaciales y ambos la comparan a la composición del archipiélago, a la movilidad que suscita y a realizar una comparación con los volcanes. Westphal la nombra la poética del archipiélago. La totalidad de este espacio está constituida por la articulación de las islas e islotes que lo componen. Explica a su vez que en el instante en que el espacio se transformara en tambaleo, esto sería emergencia. Dice Westphal que en su versión volcánica sería erupción (apud Westphal 2000: 18). Por su parte, es conveniente evidenciar las concordancias con el pensamiento rokhiano. En 1935, una fecha crucial en el cambio hacia la centralidad del paradigma espacial, De Rokha escribe en su ensayo "Estimativa y método": "porque la conciencia es, sosteniéndose en el fluir 
psíquico, 'el archipiélago del enorme océano subconsciente' y así la ciencia se resuelve en los territorios y las epopeyas del arte" (De Rokha 1935: 71).

Mientras en el poema “Apología de lo nacional y lo internacional chileno" leemos:

...los pueblos

eternos de Latinoamérica te entienden, como un toro entre montañas

y el fascismo lame tu océano de arsénico mostrando la len-

gua babosa de policía del infierno;

grita el pájaro del huracán en tu cabellera espantosa,

y el fusil de Dios lo empuña tu pueblo de oro, en cuya gran

boca está saliendo el sol de Marx, la corneta

del Hemisferio, proclama en tu garganta

el sentido insular y oceánico de tu lenguaje de volcanes;

universalmente te sucedes a ti mismo

y tus dolores son los dolores del mundo, de los que ya reple-

ta la tierra de mis abuelos...

Te hicieron los padecimientos humanos. (De Rokha 1949: 360-361)

Al igual que la referencialidad volcánica a la movilidad, la fragmentación y la evanescencia transformadora de los espacios, en Carta magna de América también se representa la emergencia del cambio o la transformación espacial con alusiones a huracanes, terremotos y movimientos de tierra.

El poema "La dual hazaña humano-geográfica. Gente grande" es revelador porque se puede apreciar nítidamente cómo la actividad literaria se transforma un proceso cartográfico o de creación de mapas mediante el lenguaje. En el poema, la voz poética se define en tanto es una voz cartógrafa encargada de proyectar en imágenes poéticas los espacios humanos por los cuales ha transitado y ha experimentado. Asimismo, y mediante su praxis poética, el poema logra una reconquista política de estos espacios de los que hace una cartografía poética. En el poema leemos:

Desde el Norte Grande te azota el látigo solar y los plantíos

de azúcar y el subsuelo del infierno te anuncian chorros de

hondo petróleo y goma terrible 
encima del pellejo de caimán del desierto, en el cual el vendabal agrícola

empuña el cuchillo de la camanchaca y se suicida en rojo; una gran meada de fuego te destina el Trópico, avanzan los carros cargados de sol por adentro,

y el Norte Verde te llena la boca de pepitas de oro, (...)

enarbolados entre la bandera floral de sus músculos;

Chile-Padre, Chile-Madre, Chile-Abuelo, tu cinturón de volcanes unánimes atruena la América,

en el lenguaje universal de tus poetas y el pánico verde

de tus terremotos, lo amarillo del horror condiciona, sumando lo antepasado al arcaico orden...

por la llamarada forestal y el animal asado que está bramando en el corazón de las fogatas con bramido grande de sangre,

el mar-Océano su caldo de santo origen y enorme enorme arquitectura enorme

el Andes gigante su gigante cadena de candado de catástrofes y el alarido infinito del infinito alarido de la materia-piedra y su esqueleto de hemisferios. (De Rokha 1949: 342-344)

En este poema y a lo largo del todo el poemario, se escucha y se defina claramente una voz poética cartográfica que se encarga de crear sus espacios americanos. Para conseguir este cometido, esta voz se sitúa en las experiencias surgidas de las realidades cambiantes y movibles del continente americano y de Chile. Así, logra darle forma sus imágenes. En definitiva, podemos concluir que en Carta magna de América se constata el desarrollo de una praxis o una acción geopoética de la insumisión y rebelde sobre América mediante la creación de múltiples y cambiantes mapas poéticos del cosmos americano. 


\section{NOTAS}

${ }^{1}$ Citamos de esta primera edición 3 poemas por Pablo de Rokha in Arenga sobre el arte (De Rokha 1949). Sin embargo, nos referimos a la obra como Carta magna de América, título con que apareció en su segunda edición en Antología 1916-1953 (De Rokha 1954).

${ }^{2}$ Además de los ensayos y el poemario de Pablo de Rokha y el poemario de Winétt de Rokha, Arenga sobre el arte incluye "Prólogo a una amiga" (De Rokha 1949: 7-10) y "Aventuras y desventuras de Arenga sobre el arte" (ídem: 363-370). Hay que señalar que, si bien las dos obras (los ensayos y los poemas) de De Rokha se identifican como libros separados en un mismo volumen, los ensayos deben entenderse como el razonamiento teórico de la obra poética.

${ }^{3}$ En Antología 1916-1953, el poemario se extiende de la página 354 hasta la página 436 (De Rokha 1954)

${ }^{4}$ En la segunda edición se eliminó el título del poema "Lenguaje del continente". El poema "Carta magna de Chile" se nombró como "Cara y sello de Chile" y "Teogonía y cosmología del libro de cocina (ensueño del infierno)" se rebautizó “Epopeya de las comidas y las bebidas de Chile (ensueño del infierno)”

${ }^{5}$ Así se puede constatar en las listas de sus publicaciones que el autor colocaba al final o al principio de sus libros. 


\section{Bibliografía}

De Rokha, Pablo (1935), "Estimativa y método", in Julio Anguita, Volodia Teitelboim (eds.), Antología de poesía chilena nueva, Santiago de Chile, Zig-Zag, pp. 71-74.

-- (1949), 3 poemas por Pablo de Rokha, in Pablo de Rokha, Arenga sobre el arte, Santiago de Chile, Multitud.

-- (1954), Carta magna de América, in Pablo de Rokha (ed.), Antología 1916-1953, Santiago de Chile, Multitud.

Deleuze, Gilles, Félix Guattari (1980), Mille plateaux, Paris, Minuit.

-- (1991), Qu'est-ce que la philosophie, Paris, Minuit.

Tally Jr., Robert T. (2013), Spatiality, New York, Routledge.

Westphal, Bertrand (2000), "Pour une approche géocritique des textes, esquisse" in La Géocritique mode d'emploi, Limoges, PULIM, pp. 9-40.

-- (2011), "Foreword", in Robert T. Tally Jr. (ed.), Geocritical Explorations, New York, Palgrave Macmillan, pp. ix-xv.

José Miguel Curet é investigador, profesor y poeta. Obtuvo su doctorado en Literatura Española e Hispanoamericana, mención Sobresaliente "Cum Laude”, de la Universidad de Salamanca, España. Posee una maestría en Literatura Francesa de Middlebury College, School in Paris y una licenciatura de la Universidad de Puerto Rico, Recinto de Río Piedras. Es especialista en la obra poética del poeta chileno Pablo de Rokha. Sus investigaciones sobre Pablo de Rokha y la vanguardia poética latinoamericana prestan especial atención a 
la transformación de los paradigmas temporales y espaciales acontecidos en la primera mitad del siglo veinte. Su trabajo sobre la poesía de Pablo de Rokha será publicado próximamente por Ediciones Tácitas de Chile. Es profesor de español, francés y humanidades de la Universidad de Puerto Rico en Río Piedras. Ha publicado dos poemarios, De visita (2002) y Revienta (2011). Sus poemas han sido incluidos en antologías y revistas de Puerto Rico, México, Estados Unidos, Canadá, España e Italia. 